\title{
Correlation between promoter methylation of the LDH-C4 gene and DNMT expression in breast cancer and their prognostic significance
}

\author{
JIANDONG ZHANG ${ }^{1}$, FENGXIA ZHANG ${ }^{2}$, FENGQIN ZHANG ${ }^{3}$, \\ HUA WU $^{1}$, BEI ZHANG ${ }^{1}$ and XIANGYUN WU ${ }^{1}$

\begin{abstract}
${ }^{1}$ Clinical Laboratory, The Third Hospital of Hebei Medical University, Shijiazhuang, Hebei 050011;
${ }^{2}$ Nursing Department, Hengshui Health School, Hengshui, Hebei 050000; ${ }^{3}$ Pathology Department, Hengshui People's Hospital of Hebei Medical University, Hengshui, Hebei 050000, P.R. China
\end{abstract}

Received August 6, 2021; Accepted October 22, 2021

DOI: $10.3892 / \mathrm{ol} .2021 .13153$

\begin{abstract}
DNA methylation plays an important role in tumorigenesis and development. The potential of aberrant DNA methylation to act as a biomarker for tumor diagnosis and prognostic evaluation is currently being explored. Lactate dehydrogenase $\mathrm{C} 4$ (LDH-C4) is a member of the cancer/testis antigen family that is expressed in a broad range of human tumor types, with particularly high expression patterns observed in lung cancer, melanoma and breast cancer. However, whether the methylation of the promoter region of LDH-C4 can be used as a tumor marker and its association with prognosis remain poorly understood. The present study aimed to determine the potential of the methylation status of LDH-C4 and DNA methyltransferase (DNMT) expression to be biological markers for the prognostic evaluation of breast cancer. Methylation-specific PCR was conducted to evaluate alterations in the methylation levels of LDH-C4. Immunohistochemical analysis was performed to assess the expression levels of DNMTs in breast cancer tissues. The association between the methylation status of LDH-C4 or the expression of DNMTs, and clinical pathological parameters was also evaluated. The results of the present study revealed that the demethylation rate of LDH-C4 in breast cancer tissues was significantly increased compared with that of adjacent tissues, and associations were identified between the demethylation of LDH-C4 and the histological grade, estrogen receptor, progesterone receptor and HER-2 status, and lymph node metastasis. The level of LDH-C4 demethylation was negatively correlated with the expression of DNMTs. Demethylation of
\end{abstract}

Correspondence to: Dr Xiangyun Wu, Clinical Laboratory, The Third Hospital of Hebei Medical University, 139 Ziqiang Road, Shijiazhuang, Hebei 050011, P.R. China

E-mail: wuxiangyunjyk@126.com

Key words: lactate dehydrogenase C4, DNA methyltransferases, methylation, expression, prognosis the LDH-C4 promoter and DNMT expression predicted an unfavorable prognosis of patients with breast cancer. In addition, demethylation of the LDH-C4 promoter, high expression of DNMT3a and DNMT3b, histological grade and lymph node metastasis were all discovered to be independent prognostic factors in patients with breast cancer. In conclusion, results of the present study indicated that the demethylation of LDH-C4 and DNMT expression levels may be closely associated with the occurrence and development of breast cancer, in addition to lymph node metastasis. Thus, both may be used to assist the clinical evaluation of prognosis.

\section{Introduction}

Breast cancer is the most common type of cancer and the leading cause of cancer-related mortality in women worldwide, with an estimated 2.26 million cases and 680,000 deaths worldwide in 2020 (1). In recent years, the survival rates have improved due to extensive research being conducted on the biological behavior of breast cancer cells $(2,3)$. However, once patients fail to respond to the traditional treatment, their quality of life and survival rate is significantly decreased (4). Therefore, it is important to identify novel tumor markers and reliable prognostic indicators to guide decision making during the treatment of breast cancer to improve disease outcomes and survival.

Lactate dehydrogenase $\mathrm{C} 4$ ( $\mathrm{LDH}-\mathrm{C} 4)$ is a tumor testis-associated antigen, which has been discovered to play an important role in the development of numerous different types of tumor, such as lung cancer, breast cancer and renal cell carcinoma. A previous study found that $\mathrm{LDH}-\mathrm{C} 4$ expression was associated with tumorigenesis and metastasis in several cancer types, including breast cancer (5). The LDH-C4 gene is located on chromosome 11 , and is the secondary replication product of the LDH-A gene (6).

At present, research into the regulation of the LDH-A gene is relatively mature (7), but the specific transcriptional regulatory mechanism of LDH-C4 remains unclear, to the best of our knowledge. It was previously reported that the integrity of the GC box and Cre site, SP and cAMP response element binding protein 1 transcription factors, and $\mathrm{CpG}$ methylation 
were involved in the activation and expression of the LDH-C4 gene $(8,9)$. DNA methylation is an epigenetic marker involved in the process of gene expression regulation; it is functionally equivalent to changes at the genetic level and reverses gene silencing. Abnormal DNA methylation plays an important role in the clinical diagnosis and prognosis of various tumor types, such as lung, breast and prostate cancer (10). Although numerous studies have reported the biological functions of LDH-C4 in healthy and cancerous tissues, to the best of our knowledge, no previous study has investigated the methylation status of LDH-C4 in breast cancer. DNA methylation is catalyzed by DNA methyltransferases (DNMTs) (11). Results of a previous study demonstrated that the expression levels of DNMTs were significantly upregulated in a number of tumor types (11), which often preceded the abnormal methylation pattern. The increase in DNMT activity promotes the deamination of methylated cytosine, increases the rate of cytosine to thymine transitions, and promotes the occurrence of point mutations in the DNA (11). It also promotes the hypermethylation of tumor suppressor genes, silences their expression and inhibits their tumor-suppressive effects (12). It was previously demonstrated that DNMTs were abnormally expressed in breast cancer (13). However, little research has been conducted on the association between DNMTs and the methylation of LDH-C4.

The present study aimed to determine the potential of LDH-C4 gene methylation and DNMT expression to act as biomarkers for the prognostic evaluation of breast cancer. In total, 136 breast cancer and adjacent tissues were collected, and methylation-specific PCR (MSP) was used to detect the methylation level of LDH-C4. Immunohistochemical (IHC) analysis was performed to measure the protein expression levels of DNMTs. The correlation between the methylation status of the LDH-C4 promoter and the expression of DNMTs was analyzed, and the association between patient clinicopathological parameters and prognosis was explored.

\section{Materials and methods}

Patient studies. Primary breast cancer and corresponding adjacent healthy tissues were obtained from 136 women patients with breast cancer (age range, 42-75 years old) following surgical resection at The Third Clinical Hospital of Hebei Medical University (Shijiazhuang, China) between July 2019 and December 2020. Data on the clinicopathological characteristics of each patient were obtained from the hospital records and pathological diagnosis, The patients did not receive chemotherapy, radiotherapy, endocrine therapy or other associated treatment before operation. The present study was approved by the Ethics Committee of The Third Clinical Hospital of Hebei Medical University (approval no. 2021-034-5) and all patients provided written informed consent prior to participation.

MSP. MSP was performed to detect the methylation status of LDH-C4. Briefly, the genomic DNA was extracted from tissues using the phenol chloroform method. The tissues were put into the EP tube and lysis buffer $\beta$-mercaptoethanol and protease $\mathrm{K}$ were added in a $56^{\circ} \mathrm{C}$ water bath. DNA extract was added, mixed well and centrifuged $\left(11,433 \mathrm{x} \mathrm{g} ; 7 \mathrm{~min} ; 4^{\circ} \mathrm{C}\right)$.
The supernatant was collected and added to double the volume of isopropanol at $20^{\circ} \mathrm{C}$ for $10 \mathrm{~min}$, and centrifuged again $\left(11,433 \times \mathrm{g} ; 7 \mathrm{~min} ; 4^{\circ} \mathrm{C}\right)$. The supernatant was removed and $70 \%$ ethanol was added into the precipitation, mixed well and centrifuged $\left(11,433 \times \mathrm{g} ; 7 \mathrm{~min} ; 4^{\circ} \mathrm{C}\right)$. The precipitation was collected and dried, ddH2O was added and the concentration was measured using ultra-micro ultraviolet spectrophotometer (Shanghai Ruiyue Experimental Equipment Co., Ltd.). Subsequently, the DNA was modified and purified using a hydrogen sulfite modification kit containing a DNA polymerase (Shanghai Yubo Biological Technology Co., Ltd.). Subsequently, a total of $3 \mu 1$ modified DNA was used as a template for PCR amplification, which was performed using the following reaction conditions: Initial denaturation at $95^{\circ} \mathrm{C}$ for $4 \mathrm{~min}$, followed by 35 cycles of denaturation at $95^{\circ} \mathrm{C}$ for $45 \mathrm{sec}$, annealing at $60^{\circ} \mathrm{C}$ for $30 \mathrm{sec}$ and extension at $72^{\circ} \mathrm{C}$ for $30 \mathrm{sec}$, and a final extension step at $72^{\circ} \mathrm{C}$ for $10 \mathrm{~min}$. The PCR products were analyzed using $2 \%$ agarose gel electrophoresis and by UV gel electrophoresis imaging and a gel image analyzer. All PCR reactions were repeated in triplicate. The methylated (M) and unmethylated (U) primers of LDH-C4 were as follows: (M) forward, 5'-TCTGGGGTGTAGCGGTCGTC-3' and reverse, 5'-GCCCACATACTAAATCACGCG-3'; and (U) forward, 5'-GTAGTTTGGGGTTGAGTGGTTGTT-3' and reverse, 5'-CACCCCCAATACATAATCACAACA-3'. Normal placental DNA modified by $\mathrm{CpG}$ methyltransferase was used as the positive control for MSP amplification. Deionized water was used as the blank control.

IHC analysis. Paraffin-embedded tissue sections (4 $\mu \mathrm{m})$ were deparaffinized in xylene and rehydrated using a graded alcohol series. The sections were subsequently washed with PBS (pH 7.2) for $5 \mathrm{~min}$ and heated in a microwave oven for $5 \mathrm{~min}$ at $65^{\circ} \mathrm{C}$ in $10 \mathrm{mmol} / \mathrm{l}$ sodium citrate buffer $(\mathrm{pH} \mathrm{6.0)}$ ) for antigen retrieval. The sections were subsequently washed with PBS and immersed in $0.3 \%$ hydrogen peroxide in methanol for $20 \mathrm{~min}$ at room temperature. After washing with PBS, the sections were incubated in 1:10 normal goat serum (5\%; Shanghai Yanjin Biotechnology Co., Ltd.) at room temperature in a humidified chamber for $45 \mathrm{~min}$ to prevent non-specific immunoglobulin binding. The sections were subsequently incubated with rabbit anti-DNMT1 (cat. no. ab19905), anti-DNMT3a (cat. no. ab226261) and anti-DNMT3b (cat. no. ab2851) polyclonal antibodies (all 1:500; Abcam) at $4^{\circ} \mathrm{C}$ overnight; the primary antibody was replaced with normal IgG to serve as the control. The sections were then thoroughly washed with PBS three times, and incubated with goat anti-rabbit polyclonal antibody (1:100; cat. no. ZB-2010; Beijing Zhongshan Golden Bridge Biotechnology Co., Ltd.) at $37^{\circ} \mathrm{C}$ for $30 \mathrm{~min}$, followed by washing 3 times with PBS. Then, the horseradish peroxidase (HRP)-conjugated streptavidin working solution was added and incubated $\mathrm{C}$ for $30 \mathrm{~min}$. A streptavidin-biotinylated HRP-based detection system (Shanghai Hexing Biological Technology Co., Ltd.) was used to determine the specific binding of each antibody. Sections were subsequently counterstained with hematoxylin at room temperature for $5 \mathrm{~min}$ and prepared for visualization using a light microscope in high power field.

The expression was determined by the intensity of the positive cells using ImageJ software (v1.8.0; National 


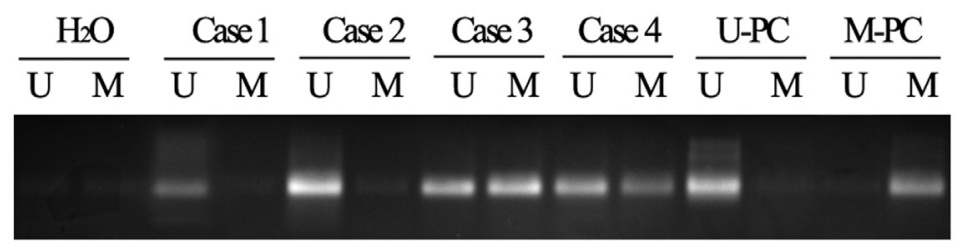

Figure 1. LDH-C4 methylation analysis of breast cancer specimens. The methylation status of the promoter region of LDH-C4 was determined using methylation-specific PCR. Cases 1 and 2, unmethylated; cases 3 and 4, methylated. U-PC, healthy placental DNA was used as the positive control for demethylated alleles; M-PC, in vitro healthy placental DNA treated with $\mathrm{CpG}$ methyltransferase was used as the positive control for methylated alleles. M, methylated; U, unmethylated; LDH-C4, lactate dehydrogenase C4; U-PC, unmethylated positive control; M-PC, methylated positive control.
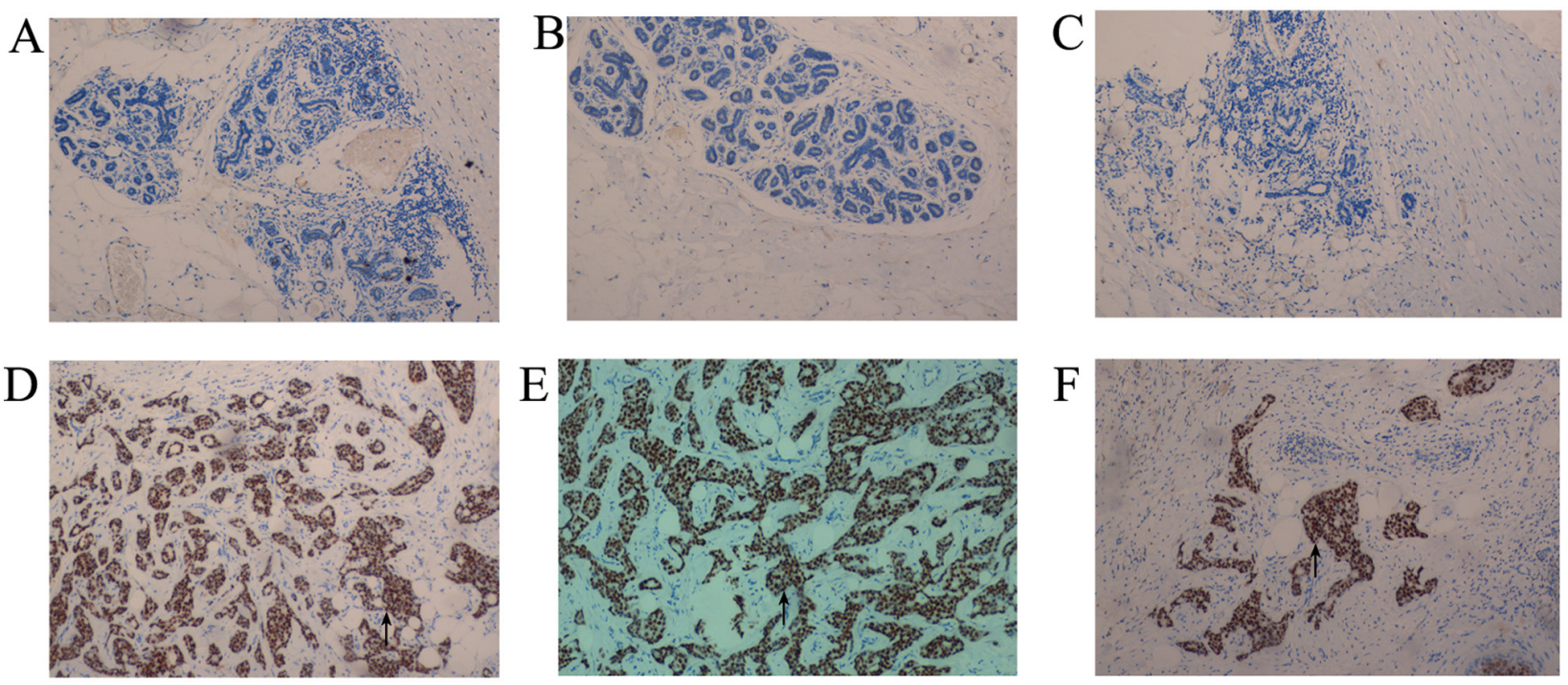

Figure 2. Immunohistochemical analysis of the expression levels of DNMTs in breast cancer and adjacent healthy tissues. Negative expression of (A) DNMT1, (B) DNMT3b and (C) DNMT3b in adjacent healthy tissues. Magnification, x20. Positive expression of (D) DNMT1, (E) DNMT3a and (F) DNMT3b in breast cancer specimens. Magnification, x20. Arrows indicate protein expression in nucleus. DNMT, DNA methyltransferase.

Institutes of Health). Briefly, the area of positive staining was scored using the following scale: $0-2$, negative expression; 3-7, positive staining (of those, 3-4, weak positive expression; and 5-7, strong positive expression). The staining intensity was graded as follows: 0 , no staining; 1 , mild staining; 2 , moderate staining; and 3, intense staining. The staining intensity and positive staining scores were multiplied together, and scores $<4$ indicated negative expression, while scores $\geq 4$ indicated positive expression.

Statistical analysis. Statistical analysis was performed using SPSS 22.0 software (IBM Corp.). Enumeration data were expressed using rate. The association between DNMT expression or the methylation status of the promoter region of LDH-C4 and clinicopathological risk factors was statistically evaluated using a $\chi^{2}$ or Fisher's exact test. The correlation between the methylation status of the $\mathrm{LDH}-\mathrm{C} 4$ promoter and the expression levels of DNMTs was detected using Spearman's rank correlation analysis. The overall survival of patients was estimated using the Kaplan-Meier method, and statistical differences between the groups were determined using a log-rank test. Univariate and multivariate analyses of overall survival according to prognostic factors were analyzed using Cox regression analysis. $\mathrm{P}<0.05$ was considered to indicate a statistically significant difference.

\section{Results}

Methylation status of the promoter region of $\mathrm{LDH}-\mathrm{C} 4 \mathrm{in}$ breast cancer tissues. Using the MSP method and primers designed to amplify the promoter region of the LDH-C4 gene, it was revealed that a marked proportion of breast cancer tissues had low levels of methylation compared with adjacent healthy tissues. In total, 59 of the 136 (43.38\%) breast cancer tissues samples contained methylation patterns in the promoter region of the LDH-C4 gene, while 121 of the 136 (88.97\%) corresponding adjacent healthy tissue samples contained methylation in the promoter region of the LDH-C4 gene (Fig. 1).

Expression of DNMT1, DNMT3a and DNMT3b in breast cancer tissues. To determine whether the methylation status of the LDH-C4 promoter region was correlated with the protein expression levels of DNMTs, their expression levels were analyzed in breast cancer and corresponding adjacent healthy tissues using IHC analysis. As shown in Fig. 2, DNMT1, DNMT3a and DNMT3b expression levels were observed in the nuclei of breast cancer cells. DNMT1, DNMT3a and DNMT3b were positively expressed in $11.76,9.56$ and $16.18 \%$ of adjacent healthy tissues, respectively, while DNMT1, DNMT3a and DNMT3b positive expression was found in 35.29, 41.91 and $39.71 \%$ of breast cancer tissues, respectively. 
Table I. Association between methylation of LDH-C4 promoter and DNMT expression and the clinicopathological factors of patients with breast cancer.

\begin{tabular}{|c|c|c|c|c|c|c|c|c|c|c|c|c|c|}
\hline \multirow{2}{*}{$\begin{array}{l}\text { Clinicopathological } \\
\text { factor }\end{array}$} & \multirow{2}{*}{$\begin{array}{c}\text { Total } \\
\text { (n) }\end{array}$} & \multicolumn{3}{|c|}{ LDH-C4 } & \multicolumn{3}{|c|}{ DNMT1, \% } & \multicolumn{3}{|c|}{ DNMT3a, \% } & \multicolumn{3}{|c|}{ DNMT3b, $\%$} \\
\hline & & $\mathrm{U}$ & M & P-value & High & Low & P-value & High & Low & P-value & High & Low & P-value \\
\hline Age, years & & & & 0.967 & & & 0.456 & & & 0.792 & & & 0.643 \\
\hline$\leq 50$ & 64 & 38 & 26 & & 21 & 43 & & 25 & 39 & & 24 & 40 & \\
\hline$>50$ & 72 & 40 & 32 & & 22 & 50 & & 29 & 43 & & 25 & 47 & \\
\hline Menopausal status & & & & 0.603 & & & 0.397 & & & 0.541 & & & 0.784 \\
\hline Pre- & 66 & 46 & 20 & & 23 & 43 & & 27 & 39 & & 25 & 41 & \\
\hline Post- & 70 & 39 & 31 & & 24 & 46 & & 24 & 46 & & 24 & 73 & \\
\hline Tumor size, $\mathrm{cm}$ & & & & 0.128 & & & 0.471 & & & 0.593 & & & 0.354 \\
\hline$<2$ & 74 & 40 & 34 & & 26 & 48 & & 28 & 46 & & 31 & 43 & \\
\hline$\geq 2$ & 62 & 37 & 35 & & 22 & 40 & & 28 & 34 & & 21 & 41 & \\
\hline Tumor histology & & & & 0.087 & & & 0.174 & & & 0.237 & & & 0.0782 \\
\hline Ductal carcinoma & 126 & 90 & 36 & & 58 & 68 & & 34 & 92 & & 48 & 78 & \\
\hline Lobular carcinoma & 9 & 4 & 5 & & 2 & 7 & & 5 & 4 & & 3 & 6 & \\
\hline Other & 1 & 1 & 0 & & 0 & 1 & & 0 & 1 & & 0 & 1 & \\
\hline TNM stage & & & & 0.689 & & & 0.258 & & & 0.264 & & & 0.741 \\
\hline I & 42 & 30 & 12 & & 9 & 33 & & 10 & 32 & & 15 & 27 & \\
\hline II & 63 & 32 & 31 & & 29 & 34 & & 37 & 26 & & 23 & 40 & \\
\hline III & 21 & 13 & 8 & & 4 & 17 & & 5 & 18 & & 9 & 12 & \\
\hline ER & & & & 0.027 & & & 0.031 & & & 0.011 & & & 0.073 \\
\hline+ & 90 & 51 & 39 & & 41 & 49 & & 38 & 52 & & 44 & 46 & \\
\hline- & 46 & 21 & 15 & & 28 & 18 & & 24 & 22 & & 25 & 21 & \\
\hline PR & & & & 0.014 & & & 0.046 & & & 0.136 & & & 0.364 \\
\hline+ & 82 & 50 & 32 & & 25 & 57 & & 32 & 50 & & 36 & 46 & \\
\hline- & 54 & 24 & 30 & & 27 & 27 & & 22 & 32 & & 20 & 34 & \\
\hline Ki-67 & & & & 0.734 & & & 0.828 & & & 0.044 & & & 0.475 \\
\hline$\leq 30 \%$ & 28 & 21 & 7 & & 9 & 18 & & 13 & 15 & & 11 & 17 & \\
\hline$>30 \%$ & 108 & 79 & 29 & & 37 & 71 & & 28 & 100 & & 56 & 52 & \\
\hline HER-2 & & & & 0.014 & & & 0.0201 & & & 0.117 & & & 0.602 \\
\hline+ & 41 & 35 & 6 & & 13 & 28 & & 16 & 25 & & 19 & 21 & \\
\hline- & 95 & 60 & 35 & & 46 & 49 & & 38 & 57 & & 40 & 55 & \\
\hline Lymph node metastasis & & & & 0.014 & & & 0.001 & & & 0.006 & & & 0.026 \\
\hline With & 71 & 35 & 36 & & 41 & 30 & & 38 & 33 & & 32 & 39 & \\
\hline Without & 65 & 21 & 44 & & 15 & 50 & & 17 & 48 & & 18 & 47 & \\
\hline Histological grade & & & & 0.034 & & & 0.043 & & & 0.026 & & & 0.039 \\
\hline I & 43 & 20 & 23 & & 18 & 25 & & 21 & 24 & & 19 & 24 & \\
\hline II & 61 & 35 & 26 & & 20 & 41 & & 26 & 35 & & 24 & 37 & \\
\hline III & 22 & 16 & 6 & & 9 & 13 & & 11 & 11 & & 8 & 14 & \\
\hline
\end{tabular}

LDH-C4, lactate dehydrogenase C4; DNMT, DNA methyltransferase; U, unmethylated; M, methylated; ER, estrogen receptor; PR, progesterone receptor; Ki-67, antigen Ki-67.

Clinical correlation between DNMT expression and the methylation status of the promoter region of $\mathrm{LDH}-\mathrm{C} 4$ and the clinicopathological factors of patients with breast cancer. To further explore the possible effects of the methylation of LDH-C4 and DNMT expression in breast cancer, the correlation between the methylation status of the promoter region of LDH-C4 and DNMT expression, and the clinicopathological factors of patients with breast cancer was determined. As shown in Table I, the methylation status of the promoter region of LDH-C4 was not associated with age, menopausal status, tumor size, tumor histology, TNM stage or antigen $\mathrm{Ki}-67$ (Ki-67) expression (Ki-67 is associated with poor clinicopathological factors (14) in breast cancer), but was significantly associated with histological grade, estrogen 

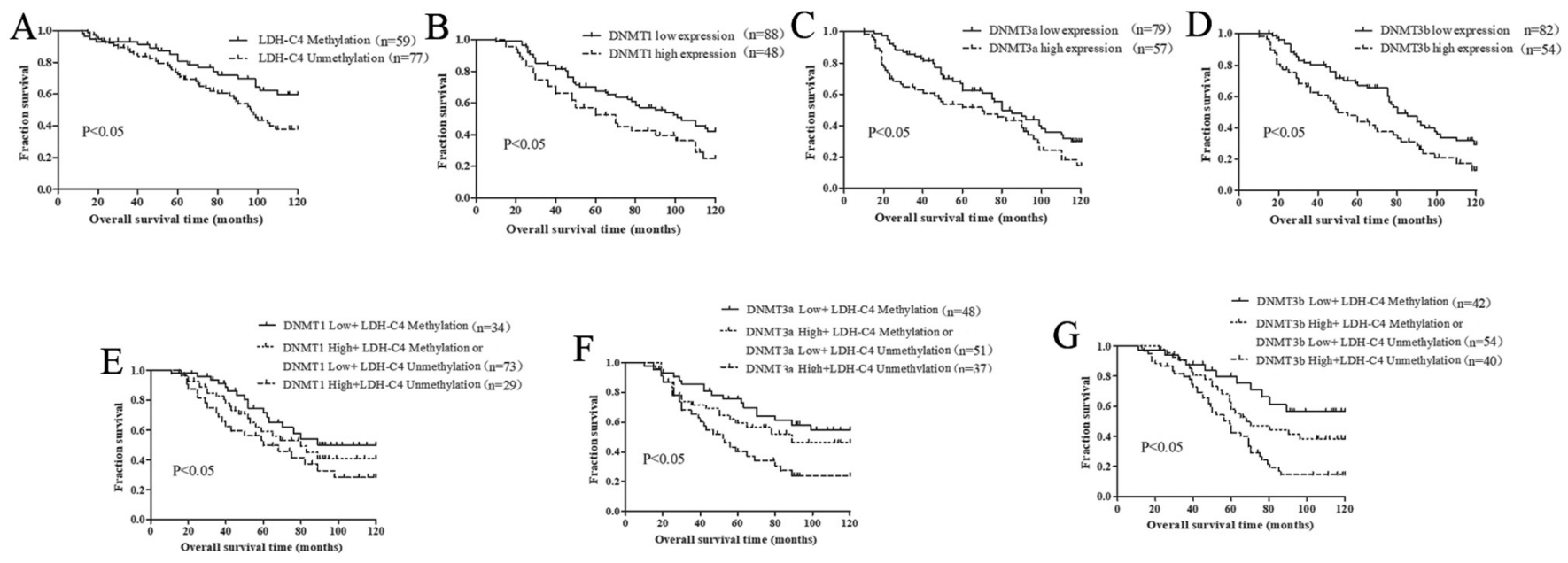

Figure 3. Kaplan-Meier curves demonstrating overall survival in association with (A) LDH-C4 methylation, (B) DNMT1, (C) DNMT3a and (D) DNMT3b expression, (E) LDH-C4 methylation and DNMT1 expression, (F) LDH-C4 methylation and DNMT3a expression, and (G) LDH-C4 methylation and DNMT3b expression in breast cancer cases. LDH-C4, lactate dehydrogenase C4; DNMT, DNA methyltransferase.

Table II. Association between promoter methylation of LDH-C4 and expression levels of DNMT1, DNMT3a or DNMT3b in breast cancer.

\begin{tabular}{lccccc}
\hline $\begin{array}{l}\text { Relative } \\
\text { expression } \\
\text { level }\end{array}$ & \multicolumn{2}{c}{ LDH-C4 } & & & \\
\cline { 2 - 5 } & $\mathrm{U}$ & $\mathrm{M}$ & $\mathrm{r}$ & $\chi^{2}$ & P-value \\
\hline DNMT1 & & & -0.273 & 6.524 & 0.018 \\
High & 37 & 11 & & & \\
Low & 40 & 48 & & & \\
DNMT3a & & & -0.216 & 4.730 & 0.032 \\
High & 40 & 17 & & & \\
Low & 37 & 42 & & & \\
DNMT3b & & & -0.298 & 7.163 & 0.010 \\
High & 29 & 25 & & & \\
Low & 48 & 34 & & & \\
\hline
\end{tabular}

LDH-C4, lactate dehydrogenase C4; DNMT, DNA methyltransferase; $\mathrm{U}$, unmethylated; $\mathrm{M}$, methylated.

receptor (ER), progesterone receptor (PR) and HER-2 status, and lymph node metastasis $(\mathrm{P}<0.05)$. The expression of DNMT1 was not associated with age, menopausal status, tumor size, tumor histology, TNM stage or Ki-67 expression, but was significantly associated with ER,PR and HER-2 status, histological grade and lymph node metastasis $(\mathrm{P}<0.05)$. The expression of DNMT3a was not associated with age, menopausal status, tumor size, tumor histology, TNM stage, and PR or HER-2 status $(\mathrm{P}>0.05)$, but was significantly associated with histological grade, ER and Ki-67 expression, and lymph node metastasis $(\mathrm{P}<0.05)$. The expression of DNMT3b was not associated with age, menopausal status, tumor size, tumor histology, TNM stage, or PR, HER-2, ER or Ki-67 expression, but was significantly associated with histological grade and lymph node metastasis $(\mathrm{P}<0.05)$. These data suggested that hypomethylated profiles of the $\mathrm{LDH}-\mathrm{C} 4$ promoter and
DNMT expression may indicate a poor prognosis of patients with breast cancer.

Association between the methylation status of the promoter region of $\mathrm{LDH}-\mathrm{C4}$ and DNMT expression in breast cancer tissues. As shown in Table II, $\chi^{2}$ analysis revealed that the unmethylated level of LDH-C4 in breast cancer tissues was inversely correlated with the expression of DNMT1 $(r=-0.273$; $\mathrm{P}=0.018)$, DNMT3a $(\mathrm{r}=-0.216 ; \mathrm{P}=0.032)$ and $\mathrm{DNMT} 3 \mathrm{~b}$ $(\mathrm{r}=-0.298 ; \mathrm{P}=0.010)$. These results indicated that DNMT1, DNMT3a and DNMT3b expression may play an important role in the demethylation of LDH-C4.

Methylation of the LDH-C4 promoter and DNMT expression are associated with the poor prognosis of patients with breast cancer. To determine the association between DNMT expression and patient survival, or the methylation status of the promoter region of LDH-C4 and patient survival, Kaplan-Meier curve analysis for overall survival was performed. Kaplan-Meier analysis revealed that patients with a demethylated LDH-C4 promoter exhibited a shorter survival time and a poorer prognosis compared with those patients with a methylated LDH-C4 promoter $(\mathrm{P}<0.05$; Fig. $3 \mathrm{~A})$. Patients with high expression levels of DNMT1, DNMT3a and DNMT3b exhibited a shorter survival time and worse prognosis compared with those with low expression levels of DNMTs (Fig. 3B-D). Moreover, a demethylated LDH-C4 promoter and high DNMT expression levels predicted an unfavorable prognosis (Fig. 3E-G).

To further investigate the prognostic factors for poor breast cancer outcomes, univariate and multivariate analyses were performed. The results of the univariate analysis revealed that overall survival was significantly associated with the methylation of the LDH-C4 promoter, and DNMT1, DNMT3a and DNMT3b expression, histological grade, ER, PR and HER-2 status, and lymph node metastasis (Table II). Multivariate analysis revealed that a demethylated LDH-C4 promoter, high expression of DNMT3a and DNMT1, histological grade and lymph node metastasis were independent prognostic factors for patients with breast cancer (Table III). 
Table III. Univariate and multivariate analyses of prognostic factors in breast cancer for overall survival.

\begin{tabular}{|c|c|c|c|c|c|c|}
\hline \multirow[b]{2}{*}{ Variable } & \multicolumn{3}{|c|}{ Univariate analysis } & \multicolumn{3}{|c|}{ Multivariate analysis } \\
\hline & HR & P-value & $95 \%$ CI & HR & P-value & $95 \%$ CI \\
\hline $\begin{array}{l}\text { LDH-C4 methylation status } \\
\text { Methylation vs. unmethylation }\end{array}$ & 2.304 & 0.015 & $1.115-3.457$ & 1.784 & 0.007 & $0.874-2.477$ \\
\hline $\begin{array}{l}\text { Expression of DNMT1 } \\
\text { High vs. low }\end{array}$ & 3.654 & $\begin{array}{l}0.036 \\
0.021\end{array}$ & $2.654-4.759$ & 2.114 & 0.001 & $0.998-3.327$ \\
\hline $\begin{array}{l}\text { Expression of DNMT3a } \\
\text { High vs. low }\end{array}$ & 2.881 & 0.047 & $1.497-4.776$ & 1.964 & 0.003 & $0.716-2.997$ \\
\hline $\begin{array}{l}\text { Expression of DNMT3b } \\
\text { High vs. low }\end{array}$ & 3.244 & & $2.229-5.436$ & 1.374 & 0.645 & $1.185-3.249$ \\
\hline $\begin{array}{l}\text { Age, years } \\
<50 \text { vs. } \geq 50\end{array}$ & 1.742 & 0.357 & $0.860-2.374$ & & & \\
\hline $\begin{array}{l}\text { Menopausal status } \\
\text { Pre- vs.post- }\end{array}$ & 1.476 & 0.184 & $0.461-1.127$ & & & \\
\hline $\begin{array}{l}\text { Tumor size, } \mathrm{cm} \\
<2 \text { vs. } \geq 2\end{array}$ & 1.655 & 0.31 & $1.417-2.652$ & & & \\
\hline $\begin{array}{l}\text { Tumor histology } \\
\text { Ductal vs. lobular }\end{array}$ & 0.87 & 0.112 & $0.650-1.117$ & & & \\
\hline $\begin{array}{l}\text { TNM stage } \\
\text { I and II vs. III }\end{array}$ & 1.336 & 0.155 & $0.897-1.968$ & & & \\
\hline $\begin{array}{l}\text { ER } \\
+ \text { vs. - }\end{array}$ & 1.774 & 0.041 & $1.156-2.427$ & 2.347 & 0.06 & $0.671-4.623$ \\
\hline $\begin{array}{l}\text { PR } \\
+ \text { vs. - }\end{array}$ & 2.668 & 0.001 & $1.497-4.634$ & 1.562 & 0.332 & $0.784-3.116$ \\
\hline $\begin{array}{l}\text { Ki- } 67 \\
\leq 30 \% \text { vs. }>30 \%\end{array}$ & 1.352 & 0.357 & $0.874-2.328$ & & & \\
\hline $\begin{array}{l}\text { HER-2 } \\
+ \text { + vs. - }\end{array}$ & 1.94 & 0.041 & $1.118-2.564$ & 2.338 & 0.075 & $0.657-4.014$ \\
\hline $\begin{array}{l}\text { Histological grade } \\
\text { I and II vs. III }\end{array}$ & 4.124 & 0.001 & $2.321-6.374$ & 2.887 & 0.001 & $1.986-4.015$ \\
\hline $\begin{array}{l}\text { Lymph node metastasis } \\
\text { Yes vs. no }\end{array}$ & 6.327 & 0.001 & $4.365-8.457$ & 3.016 & 0.001 & $0.1 .336-5.417$ \\
\hline
\end{tabular}

CI, confidence interval; HR, human epidermal growth factor receptor 2; LDH-C4, lactate dehydrogenase C4; DNMT, DNA methyltransferase; ER, estrogen receptor; PR, progesterone receptor; Ki-67, antigen Ki-67.

\section{Discussion}

Due to the increasing prevalence of breast cancer, early diagnosis and treatment are crucial for the effective prevention and control of the disease, in addition to improving the prognosis of patients (15). However, highly sensitive and specific tumor markers for the auxiliary diagnosis and prognosis prediction of breast cancer are currently limited. Therefore, it remains important to identify novel tumor markers for breast cancer (16). LDH-C4 is a nicotinamide adenine dinucleotide-dependent kinase, which exists in mammalian sperm and other germ cells (17). LDH-C4 is also a tumor testis-associated antigen, that has strong immunogenicity (18) and therefore may represent a novel target for tumor immunotherapy. Previous studies have found that LDH-C4 is highly expressed in lung cancer $(19,20)$, breast cancer (21) and renal cell carcinoma (22). It has been shown to have important clinical value as a specific molecular marker of breast cancer (21). However, the specific expression profile of LDH-C4 and its underlying molecular regulatory mechanisms remain unclear; thus, further investigations are required.

Results of a previous study demonstrated that the CpG methylation frequency in the promoter region of sperm expressing the $\mathrm{LDH}-\mathrm{C}$ gene was low, while the methylation frequency of $\mathrm{CpG}$ in liver cells without the LDH-C gene was high (23). These results suggested that methylation status may affect the activity of the LDH-C gene promoter, thus regulating the expression of the gene. Tang and Goldberg (8) previously reported that methylation plays an important role in the transcription of the LDH-C gene 
in prostate cancer tissues. Results of the present study revealed that the demethylation rate of the LDH-C4 gene in breast cancer tissues was significantly higher compared with that of adjacent tissues, suggesting that the demethylation of LDH-C4 may be closely associated with the occurrence and development of breast cancer. In addition, a correlation was identified between the methylation status of LDH-C4 and the histological grade, ER, PR and HER-2 status, and lymph node metastasis. These aforementioned pathological indexes were also closely associated with the prognosis of the disease.

DNMTs play an important role in DNA methylation (24), and the main members of the family include DNMT1, DNMT3a and DNMT3b. The expression of DNMTs is associated with aberrant methylation in tumor tissue (25), and they participate in the occurrence and development of tumors to varying degrees $(26,27)$. Previous studies have revealed that DNMTs interact with transcription factors, histone methyltransferases and microRNA to regulate a variety of tumor-related genes (28). However, to the best of our knowledge, it remains unclear whether LDH-C4 demethylation is affected by DNMTs in breast cancer. Results of the present study demonstrated that DNMT1, DNMT3a and DNMT3b proteins were expressed to differing degrees in breast cancer tissues. A previous study also indicated that DNMT expression was upregulated in breast cancer (29). Findings of the present study also indicated that the expression levels of DNMT1 were correlated with ER, PR and HER-2 expression, histological grade and lymph node metastasis. In addition, the expression levels of DNMT3a were found to be associated with histological grade, ER and Ki-67 expression, and lymph node metastasis, while the expression levels of DNMT3b were associated with histological grade and lymph node metastasis. Analysis to identify a correlation between LDH-C4 demethylation and DNMT expression revealed that the protein expression levels of DNMT were reduced in line with the demethylation of LDH-C4 in breast cancer tissues, indicating that the low expression of DNMTs may be an important biological event promoting the occurrence of LDH-C4 demethylation. The 5-year overall survival of patients with breast cancer with demethylated $\mathrm{LDH}-\mathrm{C} 4$ was also found to be significantly reduced compared with methylated LDH-C4. In addition, the prognosis of patients with LDH-C4 demethylation and high DNMT expression was poor compared with methylated LDH-C4 and low DNMT expression, respectively. Multiple Cox regression analyses also revealed that $\mathrm{LDH}-\mathrm{C} 4$ gene demethylation, and DNMT3a and DNMT1 expression were independent prognostic factors of breast cancer. However, DNMT3b expression was not found to be an independent risk factor for breast cancer.

In conclusion, the findings of the present study revealed that the expression levels of DNMTs were closely associated with the methylation level of LDH-C4 in breast cancer. The observed low expression levels of DNMT3a and DNMT3b may be an important molecular event of LDH-C4 gene demethylation, which suggests their potential use for the diagnosis and treatment of early-stage breast cancer. In addition, these markers may also have potential as comprehensive indicators to assist clinical prognosis evaluation.

\section{Acknowledgements}

Not applicable.

\section{Funding}

The present study was supported by the Health Department of Hebei Province (grant no. 20210337).

\section{Availability of data and materials}

All data generated or analyzed during this study are included in this published article.

\section{Authors' contributions}

JZ and XW confirm the authenticity all the raw data. JZ and XW designed the study. FXZ and FQZ collected the characteristics of the patients and performed the experiments. HW and BZ analyzed the data. JZ wrote the manuscript. All authors agreed to be accountable for all aspects of the research in ensuring that the accuracy or integrity of any part of the work was appropriately investigated and resolved. All authors read and approved the final manuscript.

\section{Ethics approval and consent to participate}

The present study was approved by the Ethics Committee of the Third Clinical Hospital of Hebei Medical University (approval no.2021-034-5) and all patients provided written informed consent prior to participation.

\section{Patient consent for publication}

Not applicable.

\section{Competing interests}

The authors declare that they have no competing interests.

\section{References}

1. Sung H, Ferlay J, Siegel RL, Laversanne M, Soerjomataram I, Jemal A and Bray F: Global Cancer Statistics 2020: GLOBOCAN Estimates of Incidence and Mortality Worldwide for 36 Cancers in 185 Countries. CA Cancer J Clin 71: 209-249, 2021.

2. Reis-Filho JS and Pusztai L: Gene expression profiling in breast cancer: Classification, prognostication, and prediction. Lancet 378: 1812-1823, 2011.

3. Lnning PE: Breast cancer prognostication and prediction: Are we making progress. Ann Oncol 18 (Suppl 8): viii3-7, 2007.

4. Shao Y, Sun X, He Y, Liu C and Liu H: Elevated Levels of Serum Tumor Markers CEA and CA15-3 Are Prognostic Parameters for Different Molecular Subtypes of Breast Cancer. PLoS One 10: e0133830, 2015.

5. Kong L, Du W, Cui Z, Wang L, Yang Z, Zhang H and Lin D: Expression of lactate dehydrogenase $C$ in MDA MB 231 cells and its role in tumor invasion and migration. Mol Med Rep 13: 3533-3538, 2016.

6. Goldberg E, Eddy EM, Duan C and Odet F: LDHC: the ultimate testis-specific gene. J Androl 31: 86-94, 2010.

7. Woodford MR, Chen VZ, Backe SJ, Bratslavsky G and Mollapour M: Structural and functional regulation of lactate dehydrogenase-A in cancer. Future Med Chem 12: 439-455, 2020.

8. Tang H and Goldberg E: Homo sapiens lactate dehydrogenase c (Ldhc) gene expression in cancer cells is regulated by transcription factor Sp1, CREB, and $\mathrm{CpG}$ island methylation. J Androl 30: 157-167, 2009.

9. Tang H, Kung A and Goldberg E: Regulation of murine lactate dehydrogenase $\mathrm{C}$ (Ldhc) gene expression. Biol Reprod 78: 455-461, 2008. 
10. Ding W, Chen $\mathrm{G}$ and Shi T: Integrative analysis identifies potential DNA methylation biomarkers for pan-cancer diagnosis and prognosis. Epigenetics 14: 67-80, 2019.

11. Jin B and Robertson KD: DNA methyltransferases, DNA damage repair, and cancer. Adv Exp Med Biol 754: 3-29, 2013

12. Lam TW, Tong JH, To KF, Chan A, Liew CT, Lai PB and Wong N: Correlative Analysis of DNA Methyltransferase Expression and Promoter Hypermethylation of Tumor Suppressor Genes in Hepatocellular Carcinoma. Cancer Genomics Proteomics 3 271-277, 2006

13. Mirza S, Sharma G, Parshad R, Gupta SD, Pandya P and Ralhan R: Expression of DNA methyltransferases in breast cancer patients and to analyze the effect of natural compounds on DNA methyltransferases and associated proteins. J Breast Cancer 16: 23-31, 2013.

14. Aman NA, Doukoure B, Koffi KD, Koui BS, Traore ZC, Kouyate M, Toure I and Effi AB: Immunohistochemical Evaluation of Ki-67 and Comparison with Clinicopathologic Factors in Breast Carcinomas. Asian Pac J Cancer Prev 20 73-79, 2019.

15. Parambil NA, Philip S, Tripathy JP, Philip PM, Duraisamy K and Balasubramanian S: Community engaged breast cancer screening program in Kannur District, Kerala, India: A ray of hope for early diagnosis and treatment. Indian J Cancer 56: 222-227, 2019.

16. Banin Hirata BK, Oda JM, Losi Guembarovski R, Ariza CB de Oliveira CE and Watanabe MA: Molecular markers for breast cancer: prediction on tumor behavior. Dis Markers 2014: 513158, 2014 .

17. Duan $\mathrm{C}$ and Goldberg E: Inhibition of lactate dehydrogenase $\mathrm{C} 4$ (LDH-C4) blocks capacitation of mouse sperm in vitro. Cytogenet Genome Res 103: 352-359, 2003.

18. Hogrefe HH, Kaumaya PT and Goldberg E: Immunogenicity of synthetic peptides corresponding to flexible and antibody-accessible segments of mouse lactate dehydrogenase (LDH)-C4. J Biol 264: 10513-10519, 1989.

19. Grunwald C, Koslowski M, Arsiray T, Dhaene K, Praet M, Victor A, Morresi-Hauf A, Lindner M, Passlick B, Lehr HA, et al: Expression of multiple epigenetically regulated cancer/germline genes in non-small cell lung cancer. Int J Cancer 118: 2522-2528, 2006 .
20. Chen L, Wu Q, Xu X, Yang C, You J, Chen F and Zeng Y: Cancer/testis antigen LDHC promotes proliferation and metastasis by activating the PI3K/Akt/GSK-3 $\beta$-signaling pathway and the in lung adenocarcinoma. Exp Cell Res 398: 112414, 2021.

21. Cui Z, Chen Y, Hu M, Lin Y, Zhang S, Kong L and Chen Y: Diagnostic and prognostic value of the cancer-testis antigen lactate dehydrogenase C4 in breast cancer. Clin Chim Acta 503: 203-209, 2020

22. Hua Y, Liang C, Zhu J, Miao C, Yu Y, Xu A, Zhang J, Li P, Li S, Bao M, et al: Expression of lactate dehydrogenase $\mathrm{C}$ correlates with poor prognosis in renal cell carcinoma. Tumour Biol 39: 1010428317695968, 2017.

23. Kroft TL, Jethanandani P, McLean DJ and Goldberg E: Methylation of $\mathrm{CpG}$ dinucleotides alters binding and silences testis-specific transcription directed by the mouse lactate dehydrogenase C promoter. Biol Reprod 65: 1522-1527, 2001.

24. Hervouet E, Peixoto P, Delage-Mourroux R, Boyer-Guittaut M and Cartron PF: Specific or not specific recruitment of DNMTs for DNA methylation, an epigenetic dilemma. Clin Epigenetics 10: 17, 2018.

25. He M, Fan J, Jiang R, Tang WX and Wang ZW: Expression of DNMTs and genomic DNA methylation in gastric signet ring cell carcinoma. Mol Med Rep 8: 942-948, 2013.

26. Supic G, Kozomara R, Zeljic K, Jovic N and Magic Z: Prognostic value of the DNMTs mRNA expression and genetic polymorphisms on the clinical outcome in oral cancer patients. Clin Oral Investig 21: 173-182, 2017.

27. Wu J, Shuang Z, Zhao J, Tang H, Liu P, Zhang L, Xie X and Xiao X: Linc00152 promotes tumorigenesis by regulating DNMTs in triple-negative breast cancer. Biomed Pharmacother 97: 1275-1281, 2018.

28. Turek-Plewa J and Jagodziński PP: The role of mammalian DNA methyltransferases in the regulation of gene expression. Cell Mol Biol Lett 10: 631-647, 2005.

29. Jahangiri R, Jamialahmadi K, Gharib M, Emami Razavi A and Mosaffa F: Expression and clinicopathological significance of DNA methyltransferase $1,3 \mathrm{~A}$ and $3 \mathrm{~B}$ in tamoxifen-treated breast cancer patients. Gene 685: 24-31, 2019. 